3. Dias L1, Chabner BA, Lynch TJ Jr, Penson RT. Breaking bad news: a patient's perspective. Oncologist. 2003;8(6):587-96.

4. Arnold SJ, Koczwara B. Breaking bad news: learning through experience. J Clin Oncol. 2006 Nov 1;24(31):5098-100.

5. Illescas R. El profesionalismo en la medicina. Revista del Cuerpo Médico Almenara. 2009;(3):14-8.

Correspondencia: Julio Maquera Afaray

Dirección: Unidad de infectologia, Hospital Nacional Guillermo Almenara Irigoyen, Av. Grau 800, Lima 13, Perú.

Teléfono: 51-1 324-2983 anexo 44082

Correoelectrónico:vigo_ma@hotmail.com

\section{Entamoeba histolytica: FAGOCITOSIS Y CAPTURA DE ERITROCITOS A DISTANCIA}

\section{Entamoeba histolytica: ERYTHROCYTE PHAGOCYTOSIS AND CAPTURE DISTANCE}

\author{
Rito Zerpa-Larrauri ${ }^{1,2 . a}$, Alonso Soto ${ }^{3, b}$, \\ Yrma Espinoza-Blanco ${ }^{1, c}$
}

Sr. Editor. En base a una serie de observaciones realizadas en el laboratorio del Instituto de Salud del Niño hemos podido objetivar al momento del estudio de la fagocitosis de glóbulos rojos por E. histolytica, un patrón sugerente de captura a distancia de glóbulos rojos. En el Video 1 (http://goo.gl/sQFMij) se observa claramente como los eritrocitos son atraídos e incluso deformados al momento de ser atraídos hacia la ameba. Una interesante hipótesis a plantear sería que la fagocitosis de eritrocitos por la E. histolytica podría estar mediada por estructuras proteicas proyectadas a manera de redes que facilitarían el atrapamiento de eritrocitos. La extrusión de proteínas a fin de facilitar el proceso de fagocitosis es un evento biológicamente plausible; en células fagocíticas humanas se han descrito estructuras a manera de redes constituidas por cromatina y proteínas con actividad antibacteriana las cuales se activan durante la respuesta inflamatoria (1). Por otro lado, se ha objetivado la presencia de reacomodos de las estructuras de actina que rodean a los hematíes al momento de la fagocitosis por E. histolyitica ${ }^{(2)}$. Otro aspecto observado en el video ha sido la aparente expulsión de ciertos eritrocitos, lo cual sugeriría algún mecanismo de reconocimiento para la selección de los eritrocitos a ser fagocitados.

Finalmente, en el Video 2 (http://goo.gl/U9RX3k) se muestra con claridad la presencia de hematíes siendo fagocitados en un solo polo del parásito, lo cual sugeriría la existencia de un citostoma lo cual contradice la creencia clásica de emisión de pseudópodos a partir de cualquier punto de la membrana del parásito. El uso de la microscopia electrónica ha sugerido la existencia de estructuras tubulares compatibles con la existencia de este citostoma.

Estas observaciones sugieren que la fagocitosis de hematíes por la $E$. histolyitica sería un proceso mucho más complejo de lo que habitualmente se plantea e incluiría mecanismos de atracción de hematíes y reconocimiento de los mismos así como la presencia de estructuras especializadas para la captura del eritrocito. Las comprobación de esta hipótesis tendría implicancias para la comprensión de algunas características propias de la infección por E. hystolitica como son su tendencia a disentería o su particular tropismo por el hígado.

Fuentes de financiamiento: autofinanciado.

Conflictos de interés: los autores declaran no tener conflictos de interés.

\section{REFERENCIAS BIBLIOGRÁFICAS}

1. Brinkmann V, Reichard U, Goosmann C, Fauler B, Uhlemann Y, Weiss DS, et al. Neutrophil extracellular traps kill bacteria. Science. 2004 Mar 5;303(5663):1532-5.

2. Bailey GB, Day DB, Gasque JW. Rapid polymerization of Entamoeba histolytica actin induced by interaction with target cells. J Exp Med. 1985 Aug 1;162(2):546-58.

Correspondencia: Rito Zerpa Larrauri

Dirección: Av. Río Marañón 436, Los Olivos, Lima-Perú.

Teléfono: 6481113. Cel.: 997751043

Correo electrónico:rzerpa43@yahoo.com

\footnotetext{
Instituto de Medicina Tropical "Daniel A. Carrión”, Universidad Nacional Mayor de San Marcos. Lima, Perú.

2 Instituto Nacional de Salud del Niño. Lima, Perú.

Hospital Nacional Hipólito Unanue. Lima, Perú.

Médico patólogo clínico; ${ }^{\mathrm{b}}$ médico internista; ${ }^{\mathrm{c}}$ bióloga

Recibido: 23-07-14 Aprobado: 06-08-14
}

Citar como: Zerpa-Larrauri R, Soto A, Espinoza-Blanco Y. Entamoeba histolytica: Fagocitosis y captura de eritrocitos a distancia. Rev Peru Med Exp Salud Publica. 2014;31(3):604. 